\title{
Low temperature direct-write fabrication of radio frequency identification circuit and antenna structures on polymer substrates
}

\author{
Alu, Noble O.*, Oberafo, Anthony A., Iwok, Unwana U., Adama, Kenneth K., \\ Imalerio, Thomas I.
}

Physics Advanced Laboratory, Sheda Science \& Technology Complex, P. M. B. 181, Garki - Abuja

\section{Email address:}

noble.alu@gmail.com (N. O. Alu)

\section{To cite this article:}

Alu, Noble O., Oberafo, Anthony A., Iwok, Unwana U., Adama, Kenneth K., Imalerio, Thomas I.. Low Temperature Direct-Write Fabrication of Radio Frequency Identification Circuit and Antenna Structures on Polymer Substrates. International Journal of Materials Science and Applications. Vol. 3, No. 3, 2014, pp. 84-87. doi: 10.11648/j.ijmsa.20140303.12

\begin{abstract}
We report the direct-write fabrication of electric circuits on polyethylene terephthalate (PET) substrates by a low temperature technique. To demonstrate the utility of the concept, Radio Frequency Identification Circuit and Antenna Structures were fabricated on polyethylene terephthalate (PET), using a 300 dpi drop-on-demand HP DeskJet system. First, each substrate was prepared by low frequency atmospheric plasma etching, followed by tin (II) chloride treatment to enhance wetting. Then a catalytic silver seed layer pattern was bubble-jet printed onto the surface. Finally, the substrate was developed in a copper electroless plating bath for $10 \mathrm{~min}$. to yield a $2.5 \mu \mathrm{m}$ copper film with a sheet resistance of $3.4 \Omega$ sq. The as-deposited film was shiny with a surface roughness of less than $8.7 \mathrm{~nm}$, which is about $0.35 \%$ of the film thickness. The films were characterized by SEM, EDX, profilometry, optical microscopy, and four-point probe resistivity measurement. This technology may be adapted for the direct-write fabrication of antenna structures for communication devices and space science applications.
\end{abstract}

Keywords: Direct-Write Fabrication, Silver Seed Layer, Characterization

\section{Introduction}

The industrial standard for fabricating electric circuits is a subtractive process in which copper-clad boards are coated with a resist and, after lithography, is subsequently etched chemically to produce the circuit lines in a process which is not only expensive but also suffers from high material wastage [1]. In recent times, however, the direct-write farbrication (DWF) of electronic and optoelectronic devices have attracted much attention as it dispenses with the need for expensive lithography, vacuum processes and expensive equipment associated with the conventional process. DWF encompasses a wide range of technologies which enable the rapid farbrication of two and three-dimensional structures by the selective deposition or removal of materials in a layer by layer manner. The key technologies include nozzle dispensing processes, such as inkjet printing, transfer methods and laser systems. In this study, we have applied drop on demand ink-jet printing for the direct-write farbrication of electric circuits on polymer substrates at room temperature. In our process, silver nano-particles are inkjet-printed on a pretreated substrate and serve as the catalytic seed layer for subsequent electroless deposition of copper, thus enabling direct fabrication of electric circuits on a wide variety of substrates directly from a CAD file at low temperatures.

It has been shown that the surface pretreatment step, for instance, by the introduction of self-assembled monolayers (SAM) and polyelectrolyte multilayers (PEM) is key to the successful sensitization of the substrate for subsequent electroless metal plating. Cheng et al [2] used alternating layers of cationic poly (allylamine) hydrochloride and anionic poly (acrylic acid) (PAA) to form a self-assembled polyelectrolyte multilayer, microscopic examination of such films revealed a highly porous surface that enabled highly efficient anchorage of the catalyst and resulted in the growth of coherent and adherent films of copper during subsequent electroless copper plating. We have found that simple treatment with acidic tin (II) chloride followed by dilute hydrazine solution and rapid drying was enough to sensitize the surface for subsequent deposition of a catalyst and 
electroless plating. Another method that have been used for the direct-write farbrication of electric circuit is direct ink-jet printing of metallo-organic decomposition inks [3], metal nanoparticle inks or mixtures of the two and subsequent thermal decomposition and sintering to yield metal thin films. In this case, however, the required thermal treatment at temperatures in excess of $300^{\circ} \mathrm{C}$ precludes the use of thermally-sensitive substrates such as polymers in addition to the challenge of formulating such inks and ensuring adequate adhesion between the metal film and the substrate [4].

\section{Experimental}

\subsection{Materials}

The chemicals used were obtained from MERCK (SA), and include, PEG 200 (Mw. 200) Sodium hydroxide $(\mathrm{NaOH})$, Hydrochloric Acid $(\mathrm{HCl})$ (25\% solution), copper sulphate, $\left(\mathrm{CuSO}_{4} \cdot 5 \mathrm{H}_{2} \mathrm{O}\right)$ formaldehyde $(\mathrm{HCHO})$, EDTA Disodium salt $\left(\mathrm{C}_{10} \mathrm{H}_{14} \mathrm{~N}_{2} \mathrm{Na}_{2} \mathrm{O}_{8} 2 \mathrm{H}_{2} \mathrm{O}\right)$, tin (II) Chloride dihydrate $\left(\mathrm{SnCl}_{2} 2 \mathrm{H}_{2} \mathrm{O}\right)$, soluble starch, ethylene glycol $\left(\mathrm{CH}_{2}(\mathrm{OH}) \mathrm{CH}_{2} \mathrm{OH}\right)$, silver nitrate $\left(\mathrm{AgNO}_{3}\right)$ and potassium ferrocyanide $\left(\mathrm{K}_{4} \mathrm{Fe}(\mathrm{CN})_{6} 3 \mathrm{H}_{2} \mathrm{O}\right)$. All chemicals were of analytical grade and were used without further purification. Distilled water was exclusively used in all aqueous solutions and rinsing procedures.

\subsection{Instrumentation}

The direct-write fabrication was carried out with HP DeskJet 1000 J110 series printer with a print head resolution of 300 dpi. Track widths and thicknesses were determined using a Veeco Dektak 150 profilometer. Scanning electron microscopy (SEM) images were acquired with Carl Zeis EVO series high resolution scanning electron microscope. The electrical resistance was measured by the 4-point probe technique using a Signatone 4-point resistivity apparatus, while Optical micrographs were obtained with an Interference microscope (Carl Zeiss Axioscope). X-ray microanalysis was carried out with INCA EDX analyzer and Ink viscosities were measured using Ostwald glass capillary viscometer, while surface tension was determined by the capillary rise method (ASTM D1331-11).

\subsection{Synthesis of starch-capped silver nanoparticles}

We synthesized silver nanoparticles using a simple hydrothermal route in which soluble starch acted as both the capping agent and reductant [5]. The silver nanoparticles so-prepared had a particle size of $32-56 \mathrm{~nm}$ as determined from scanning electron micrographs.

\subsection{Ink formulation}

The ink formulation process involved the adjustment of both viscosity and surface tension of the silver nanoparticle catalyst. We have utilized sodium dodecyl sulphonic acid as a surface active agent to modify the surface tension, and PEG 200 as both a viscosity modifier and humectant.

\subsection{Fabrication Processes}

We fabricated Radio Frequency Identification Circuit and Antenna Structures on 8.27 x 11.69 inch-size polyethylene terephthalate (PET) substrates using a drop-on-demand HP DeskJet $1000 \mathrm{~J} 110$ series printer according to the following procedure. First, the PET film was cleaned with Neutracon (Decon), rinsed with distilled water, blow-dried with hot air, then plasma-etched for 30 minutes at atmospheric pressure by passing through a corona discharge head maintained at $15 \mathrm{KV}$, The plasma treatment was done to enhance the wetting characteristics of the surface by destroying surface organic contaminants, and to induce polarity [6]. Then, the substrate was successively treated with $0.01 \mathrm{M} \mathrm{SnCl}_{2}$ maintained at a $\mathrm{PH}$ of 2 , using $25 \% \mathrm{HCl}$ at room temperature for $5 \mathrm{~min}$, rinsed first with distilled water and then $40 \mathrm{mM}$ hydrazine solution and, thereafter, blow-dried in hot air and stored in a desiccator for subsequent inkjet printing and electroless copper-plating. We utilized National Instruments Circuit Design Suite (NI Multisim 10 and Utilboard) for schematic capture and PCB design/routing. The printer was then loaded with the silver nanoparticle ink and the PCB pattern printed on the treated PET film. At this point, the print-out consisted of invincible pattern of silver nanoparticles which served as seed for subsequent copper electroless plating. The plating bath contained $\mathrm{CuSO}_{4} \cdot 5 \mathrm{H}_{2} \mathrm{O} 18 \mathrm{~g} / \mathrm{L}, \mathrm{C}_{10} \mathrm{H}_{14} \mathrm{~N}_{2} \mathrm{Na}_{2} \mathrm{O}_{8} 2 \mathrm{H}_{2} \mathrm{O} 48 \mathrm{~g} / \mathrm{L}$, $\mathrm{HCHO} 22.5 \mathrm{~mL} / \mathrm{L}, \mathrm{K}_{4} \mathrm{Fe}(\mathrm{CN})_{6} 3 \mathrm{H}_{2} \mathrm{O} 57.3 \mathrm{mg} / \mathrm{L}$ [7]. The $\mathrm{pH}$ of the solution was adjusted to 13 with $\mathrm{NaOH}$ and concentrated $\mathrm{HCl}$. The plating was then carried out for $10 \mathrm{~min}$. at room temperature to yield coherent $2.5 \mu \mathrm{m}$ copper films at a plating rate of $15 \mu \mathrm{m} / \mathrm{h}$ printer.

\section{Results and discussion}

Figure 1 shows the fabricated circuit. It was found that appropriate treatment of the PET substrate surface, coupled with appropriate ink formulation and printing parameters were keys to satisfactory film properties, like ensuring overlap of successive droplets and thus avoiding the formation of island structures consisting of unconnected dots.

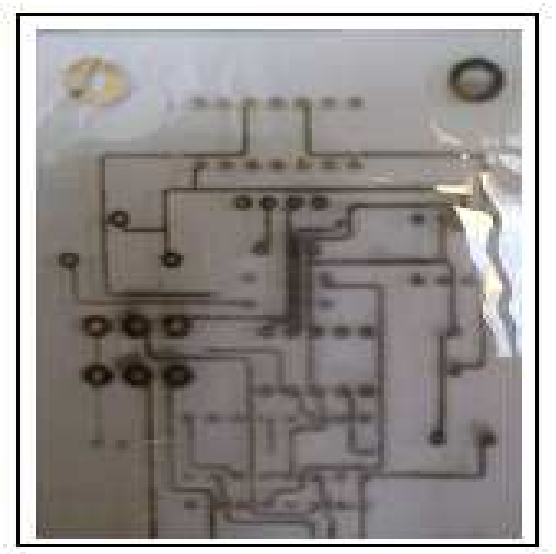

Figure 1: Printed circuit produced by direct-write fabrication on PET 2.2. Table (SciencePG-Level2-single-line) 
The degree of overlap is known to be a function of not only the print strategy, but also of the surface energy of both the ink and the substrate [8]. In our case, we have concentrated on the minimization of the surface energy of the ink by appropriate ink formulation and of the substrate, by appropriate surface treatment. Under optimized conditions, adherent, coherent, conductive, and visually shiny copper films were formed on the substrate after $10 \mathrm{~min}$ of electroless plating. The measured thickness was found to be $2.5 \mu \mathrm{m}$ with a surface roughness of $8.7 \mathrm{~nm}$, which is about $0.35 \%$ of the film thickness, thus explaining the reflective appearance. The as-deposited films were also quite conductive even without annealing with a sheet resistance of $3.4 \Omega$ sq. considering the extreme simplicity of the substrate pretreatment and low-cost printer involved in this study, these results may be considered as promising. We further scrutinized the morphology of the plated copper films. Our study shows that under appropriate conditions, dense and relatively non-porous films were formed. Figures 2(a) and (b) show the high resolution Scanning Electron Microscope image of the obtained copper films. We observe a well-packed structure consisting of about $50 \mathrm{~nm}$ thick grains in addition to what appears to be randomly distributed clusters which we attribute to excessive nucleation in some sites leading to uneven growth. The nanometer-sized grains is expected to lead to improvement in yield stress leading to more ductile films since yield stress increases with decreasing grain size as expressed by the inverse power law known as the Hall-Petch relation [9] [10]

$$
\sigma_{y}=\sigma_{0}+K / \sqrt{d}
$$

Where ' $K$ ' is a constant and ' $d$ ' is the mean grain size.

We also observe the absence of film consolidation artifacts such as cracking and coffee stains, as is evident in the lower magnification optical micrograph (Figure 3). This result agrees with work by Chouz et al [11]. We do not find these surprising in view of the fact that the inkjet-printed catalytic layer only serves to initiate subsequent electroless copper growth, which has a leveling effect by obliterating minor imperfections.

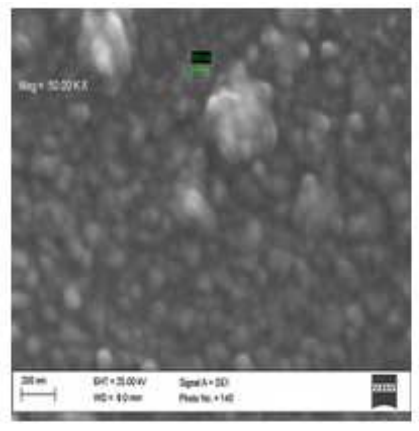

(a)

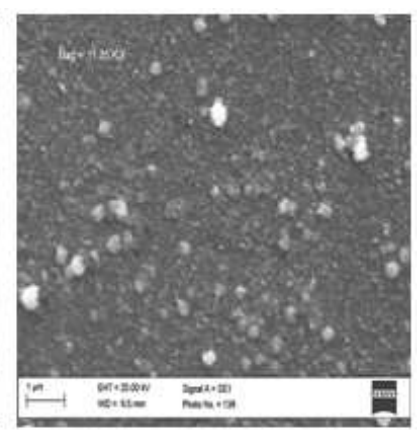

(b)
Figure 2: SEM images of the inkjet printed copper at two different magnifications showing tightly packed grains and cluster formation.

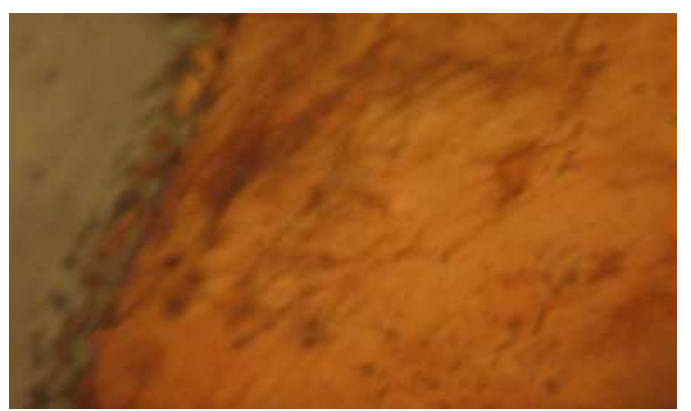

Figure 3: Optical image of inkjet-printed copper film showing absence of coffee stains and voids. However, satellite drops are clearly evident.

Figure 4 presents dark field view, showing satellite drops at the edges of the film. Satellite drops are formed when the primary droplet breaks up into smaller drops. This effectively reduces edge definition and leads to blurring. This issue is intrinsic to the technology itself and has to do with the ink discharge condition. Cheng et al [12] disclosed a method for controlling satellite drop formation which involves shaping the waveform of the driving signals. Their method resulted in signicant reduction in satellite drop formation. The minimum feature size we achieved with the inkjet print head was $100 \mu \mathrm{m}$. (Minimum feature sizes lower than $20 \mu \mathrm{m}$ had in fact been reported in the past [13], but these involved the use of state-of-the-art inkjet print heads.) Our attempts to reduce the line width even further were met with difficulty in maintaining continuity. This limitation is believed to be wholly a consequence of the print head used and lack of specialized print algorithm. We consider this as an acceptable trade-off between cost and quality.

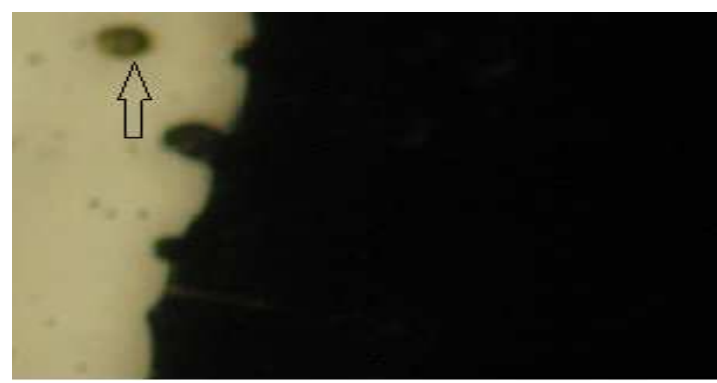

Figure 4: Optical image of inkjet-printed copper film showing absence of coffee stains and voids. However, satellite drops are clearly evident.

Figure 5 presents the EDX analysis of the copper films deposited on soda lime glass by electroless plating. As shown, the film consists essentially of pure copper, while the other peaks originate from the substrate.

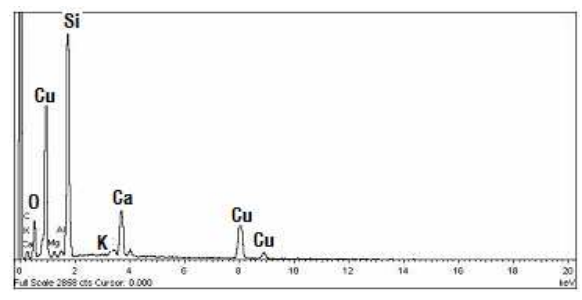

Figure 5: EDX analysis of copper film deposited on soda lime glass by electroless plating. 


\section{Conclusion}

We have been able to demonstrate room temperature fabrication of electric circuits on PET substrates using direct-write technology. Despite the simplicity of using DeskJet printer, and lack of specialized print algorithm, line widths of about $100 \mu \mathrm{m}$ were fabricated, thus opening up application in rapid prototyping and manufacturing of electric circuits using simple off-the-shelf printers for low power electronics. We have also developed a robust pretreatment process that enables the functionalization of polymer substrates for selective area electroless plating without the complication of multi-step pretreatment strategies.

\section{References}

[1] M. W. Jawitz, in Printed Circuit Board Materials Handbook, New York, McGraw-Hill, 1997.

[2] K. Cheng, Y. Ming-Huan, W. W. Wanda, C.-Y. Chiu, J. C. Huang, Y. Tai-Fa and Y. Yang, "Ink-Jet Printing, Self-Assembled Polyelectrolytes, and Electroless Plating: Low Cost Fabrication of Circuits on a Flexible Substrate at Room Temperature," Macromol. Rapid Commun., p. 247-264, 2005.

[3] K. F. Teng and R. Vest, "A microprocessor-controlled ink jet printing system for electronic circuits," IEEE Trans. Indust. Electron, pp. vol. 9, no. 11, pp. 591-592, 1988.
[4] J. B. Szczech, C. M. Megaridis, D. R. Gamota and J. Zhang, Transactions on Electronics Packaging Manufacturing, IEEE, 2002 , pp. 25, 26.

[5] N. Vigneshwaran, R. Nachane, R. Balasubramanya and P. Varadarajan, " A novel one-pot 'green' synthesis of stable silver nanoparticles using soluble starch," Carbohydrate Research, vol. 341, no. 12, pp. 2012-2018, 2006.

[6] S.-R. Veronica, M. Marie-Beatrice and S. G. Yeates, "Inkjet printing of 3D metal-insulator-metal crossovers," Reactive \& Functional Polymers, p. 1052-1058, 2008.

[7] Y. M. Lin and S. C.Yen, Appl. Surf. Sci., pp. 178, 116, 2001.

[8] P. Smith, D. Shin, J. Stringer and B. Derby, Journal of Materials Science 41, p. 415, 2006.

[9] E. O. Hall, Proc. Phys. Soc. London, pp. 64, 747, 1951.

[10] N. J. Petch, J. Iron Steel Inst., pp. 174, 25, 1953.

[11] C.-Y. K. Chouz and Kan-Sen, "Electroless Copper Plating onto Printed Lines of Nanosized Silver Seeds," Electrochemical and Solid-State Letters 10 (3), pp. 32 - 34, 2007.

[12] K. Cheng, W. W. Chiu, C. Jang, C. Lai, Y. K. Ho and J. Chang, "NIP 19: International Conference on Digital Printing Technologies", p. 309-313., 2003.

[13] J. Heinz and C. H. Hertz, "Ink-jet printing," Advances in Electronics and Electron Physics, vol. 65, p. 91-171, 1985. 